Article

\title{
Short- and Long-Term Outcomes of Left Main Coronary Artery Stenting in Patients Disqualified from Coronary Artery Bypass Graft Surgery
}

\author{
Wojciech Jan Skorupski *, Marta Kałużna-Oleksy (D), Maciej Lesiak (D, Aleksander Araszkiewicz, \\ Włodzimierz Skorupski, Stefan Grajek, Przemysław Mitkowski, Małgorzata Pyda and Marek Grygier
}

Citation: Skorupski, W.J.;

Kałużna-Oleksy, M.; Lesiak, M.;

Araszkiewicz, A.; Skorupski, W.;

Grajek, S.; Mitkowski, P.; Pyda, M.;

Grygier, M. Short- and Long-Term

Outcomes of Left Main Coronary

Artery Stenting in Patients

Disqualified from Coronary Artery

Bypass Graft Surgery. J. Pers. Med.

2022, 12, 348. https://doi.org/

10.3390/jpm12030348

Academic Editor: Elizabeth Vafiadaki

Received: 24 January 2022

Accepted: 22 February 2022

Published: 25 February 2022

Publisher's Note: MDPI stays neutral with regard to jurisdictional claims in published maps and institutional affiliations.

Copyright: (C) 2022 by the authors. Licensee MDPI, Basel, Switzerland. This article is an open access article distributed under the terms and conditions of the Creative Commons Attribution (CC BY) license (https:// creativecommons.org/licenses/by/ $4.0 /)$.

\author{
1st Department of Cardiology, Poznań University of Medical Sciences, 61-848 Poznań, Poland; \\ marta.kaluzna@wp.pl (M.K.-O.); maciej.lesiak@skpp.edu.pl (M.L.); aaraszkiewicz@interia.pl (A.A.); \\ w.skorupski@wp.pl (W.S.); stefan.grajek@skpp.edu.pl (S.G.); przemyslaw.mitkowski@skpp.edu.pl (P.M.); \\ malgorzata.pyda@skpp.edu.pl (M.P.); mgrygier@wp.pl (M.G.) \\ * Correspondence: wojciechjan.skorupski@gmail.com; Tel.: +48-61-8549222
}

\begin{abstract}
The study aims to evaluate the short- and long-term outcomes of left main percutaneous coronary interventions (LM PCI) in patients disqualified from coronary artery bypass graft surgery (CABG). We included 459 patients (mean age: $68.4 \pm 9.4$ years, $24.4 \%$ females), with at least 1-year follow-up; 396 patients in whom PCI was offered as an alternative to CABG (Group 1); and 63 patients who were disqualified from CABG by the Heart Team (Group 2). The SYNTAX score (29.1 \pm 9.5 vs. $23.2 \pm 9.7 ; p<0.001)$ and Euroscore II value $(2.72 \pm 2.01$ vs. $2.15 \pm 2.16 ; p=0.007)$ were significantly higher and ejection fraction was significantly lower ( $46 \%$ vs. $51.4 \% ; p<0.001)$ in Group 2. Patients in Group 2 more often required complex stenting techniques (33.3\% vs. $16.2 \% ; p=0.001)$. The procedure success rates were very high and did not differ between groups (100\% vs. $99.2 \% ; p=0.882)$. We observed no difference in periprocedural complication rates $(12.7 \%$ vs. $7.8 \% ; p=0.198)$, but the long-term all-cause mortality rate was higher in Group 2 (26\% vs. $21 \%$; $p=0.031)$. LM PCI in patients disqualified from $C A B G$ is an effective and safe procedure with a low in-hospital complication rate. Long-term results are satisfactory.
\end{abstract}

Keywords: coronary artery disease; LM stenting; multivessel disease; heart team; PCI

\section{Introduction}

The left main coronary artery (LM) provides over 75\% of the blood flow to the left ventricular (LV) myocardium, even in patients with dominant right coronary artery (RCA) [1]. Therefore, a significant LM stenosis puts a patient at high risk since it can endanger nearly the entire LV myocardium. Furthermore, LM stenosis characterizes the worst prognosis of all forms of coronary artery disease (CAD). LM stenosis is detected in about 4-9\% of patients undergoing coronary angiography $[2,3]$.

Earlier studies showed that the 3-year mortality rate in patients with unprotected left main coronary artery disease (LM-CAD) receiving only medical therapy was nearly $50 \%$ [4-6]. Coronary artery bypass graft surgery (CABG) improves survival rates compared with medical therapy. It has been the standard of care for the LM-CAD for nearly four decades [7-9]. However, advances in percutaneous coronary interventions (PCI) lead to the reconsideration of the PCI role in the LM-CAD treatment $[10,11]$. Contemporary PCI standards for LM-CAD include pre-procedural imaging, functional assessment, procedural planning using new-generation drug-eluting stents (DES), lesion preparation, proximal optimization technique, kissing balloon technique, post-procedural imaging, and potent dual antiplatelet therapy [12].

Current European Society of Cardiology (ESC) guidelines still favor CABG as the only treatment method for LM disease with diffuse CAD [13]. However, in less advanced CAD, 
LM PCI is a method of choice. The safety and efficacy of PCI in comparison with CABG in patients with unprotected LM-CAD were proved in randomized trials with the use of first-generation and second-generation DESs [14-17]. Present guidelines apply only to patients with coronary anatomy suitable for both procedures and with a low risk of death during surgery [13]. Thus, many patients do not meet the guidelines criteria. Based on current recommendations, the Heart Team should select the optimal treatment strategy, considering the patient's individual characteristics [13]. However, clinical status and severe comorbidities in many patients do not allow CABG performance. In these patients, LM $\mathrm{PCI}$ is the only alternative and should be considered the best treatment choice. Moreover, it should be underlined that patients disqualified from CABG are generally excluded from clinical trials; thus, the real results of the procedure and long-term follow-up data are not well known in this population. Therefore, personalized patient-to-patient decisions are crucial. Additional information would be extremely useful in supporting the clinical decision-making process and developing future medical progress towards better LM-CAD disease treatment.

We aimed to evaluate the short- and long-term outcomes of LM PCI in patients disqualified from CABG surgery in a real-world setting.

\section{Materials and Methods}

\subsection{Study Population}

From January 2015 to June 2019, 613 consecutive patients underwent LM PCI in our department. Subsequent 459 patients, with at least 1-year follow-up, were included in a prospective registry presented in this paper (Figure 1).

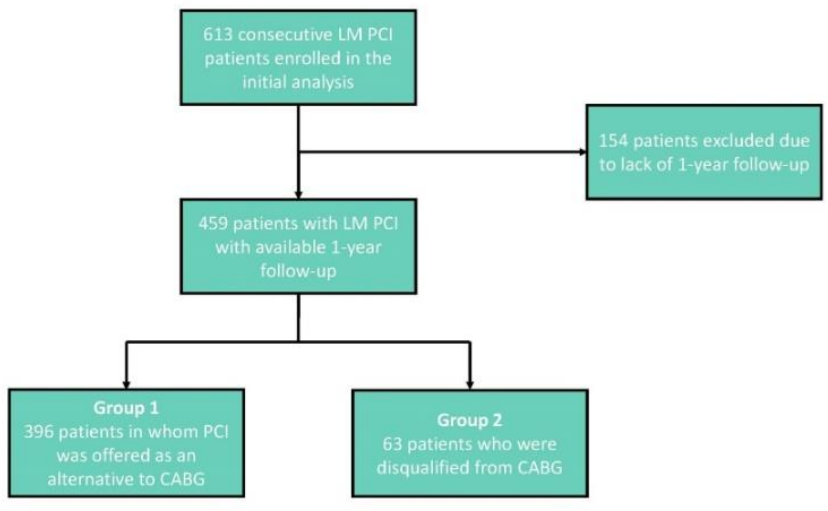

Figure 1. Flowchart presenting the inclusion and exclusion criteria. LM-Left Main, PCI-Percutaneous Coronary Intervention, CABG—Coronary Artery Bypass Graft.

We included patients with $\geq 50 \%$ diameter stenosis of LM with or without the involvement of left anterior descending artery (LAD), ostial circumflex coronary artery (LCx), or both. In patients with moderate lesions, intravascular ultrasound imaging (IVUS) was used to confirm the significance of the lesion, with a cut-off value of minimal lumen area of $6.0 \mathrm{~mm}^{2}$ for LM. Patients with LM equivalent disease, i.e., distal bifurcation Medina 0.1.1, who presented $<70 \%$ stenoses of the ostial LAD or LCx without any evidence of ischemia in its myocardial distribution, were not included in the study [16].

The study group consisted of 396 patients in whom PCI was offered as an alternative to CABG (Group 1) and 63 patients who were disqualified from CABG (Group 2). Group 1 consisted of patients eligible for both PCI and CABG. In Group 2, all patients had clear angiographic indications to $C A B G$, but were disqualified from the procedure by two experienced cardiac surgeons because of prohibitive perioperative risk due to serious cardiac or extra-cardiac comorbidities (Table 1). 
Table 1. Clinical conditions leading to CABG disqualification in the study group.

\begin{tabular}{|c|c|c|c|}
\hline \multicolumn{4}{|c|}{ Disqualification Factors } \\
\hline Cardiac Factors & Number of Patients & Extra-Cardiac Factors & Number of Patients \\
\hline Enlargement of LV (LVEDD > $70 \mathrm{~mm}$ ) & 6 & Severe obesity $\left(\mathrm{BMI}>35 \mathrm{~kg} / \mathrm{m}^{2}\right)$ & 19 \\
\hline LVEF $<30 \%$ & 4 & Renal failure (GFR < 30 mL/min) & 13 \\
\hline $\begin{array}{l}\text { Diffusely diseased peripheral segments } \\
\text { (no useful for CABG) }\end{array}$ & 3 & Multilevel peripheral atherosclerosis & 10 \\
\hline \multirow[t]{4}{*}{ Valve diseases-not eligible for surgery } & 2 & Frailty syndrome & 9 \\
\hline & & Advanced COPD (GOLD $\geq 3$ ) & 8 \\
\hline & & Mental disorders & 7 \\
\hline & & Others * & 23 \\
\hline \multicolumn{4}{|c|}{$\begin{array}{l}\text { LV-Left Ventricle, LVEDD_Left Ventricular End Diastolic Diameter, LVEF-Left Ventricle Ejection Fraction, } \\
\text { CABG-Coronary Artery Bypass Graft, BMI-Body Mass Index, GFR-Glomerular Filtration Rate, COPD- } \\
\text { Chronic Obstructive Pulmonary Disease, GOLD-The Global Initiative for Chronic Obstructive Lung Disease; } \\
\text { * Advanced oncology disease, musculoskeletal disorders, age over } 85 \text { years, carotid arteries stenosis, active } \\
\text { ulcerative colitis. }\end{array}$} \\
\hline
\end{tabular}

\subsection{Study Procedures}

After a Heart Team meeting with a cardiac surgeon, invasive procedures were performed by experienced invasive cardiologists at a high-volume referral center with cardiac surgery department on-site. Patients were treated with the intention to achieve complete revascularization of all major vessels with significant lesions. All bifurcation lesions were assessed angiographically according to the Medina classification [18]. Periprocedural myocardial infarction (type 4a) was diagnosed based on ESC Fourth Universal Definition of Myocardial Infarction (2018) [19]. The use of glycoprotein IIb and IIIa inhibitors and imaging modalities (IVUS, OCT) was at the operator's discretion. In the analyzed population, IVUS or OCT imaging was used in $142(30.9 \%)$ patients, which was beyond this analysis's scope.

We analyzed the clinical and angiographic data of these patients, as well as the short- and long-term outcomes. Baseline clinical data were collected for each patient at the index procedure. Main procedural data with all periprocedural and in-hospital complications were also collected and analyzed. The follow-up data were collected by telephone contact or based on the official records of the National Health Fund. Terminal patients whose expected survival was less than one year were excluded from long-term survival analysis. Chronic kidney disease (CKD) was defined as a decreased kidney function based on glomerular filtration rate (GFR) $<60 \mathrm{~mL} / \mathrm{min}$ within the last three months and was calculated by the Cockcroft-Gault formula [20]. Troponin analysis was not available in the whole analyzed population, but only in patients included in the prospective part of the study, in which troponin levels were measured routinely before and between 12 and 24-h after the procedure.

The registry conformed to the ethical guidelines of the 1975 Declaration of Helsinki and was granted ethics approval by the Institutional Review Board of the Poznan University of Medical Sciences.

\subsection{Study Endpoints}

The composite primary outcome of the study was defined as the rate of in-hospital death, in-hospital myocardial infarction, and long-term all-cause death.

\subsection{Statistical Analysis}

Statistical analysis was performed using STATISTICA 12 (Tibco Software Inc., Palo Alto, CA, USA). A standard descriptive statistic was applied in the analysis. All continuous variables are presented as means (standard deviation) or medians (interquartile range). The normality distribution was analyzed using the Shapiro-Wilk test. The statistical significance 
of differences was tested with the $t-S t u d e n t$ test or nonparametric U Mann-Whitney test. Categorical variables were reported as counts or percentages and compared by tests for proportions. The Kaplan-Meier method was used to calculate the survival probability at follow-up. The survival curves were compared with a log-rank test. A two-sided $p$ value of $<0.05$ was considered significant for all the tests.

\section{Results}

\subsection{Study Population}

The study cohort consisted of 459 consecutive patients who underwent LM PCI (mean age: $68.4 \pm 9.4$ years, $75.6 \%$ males). Patients baseline characteristics are presented in Table 2 . Patients disqualified from CABG (Group 2) were older (70.9 \pm 10.9 years vs. $68 \pm 9.1$ years; $p=0.024)$, with more females (34.9\% vs. $22.7 \% ; p=0.036)$, and with higher prevalence of CKD (54\% vs. $31.6 \% ; p<0.001)$. The groups did not differ in other cardiovascular risk factors. There were more patients with prior CABG in Group 1. This difference results from the fact that patients after CABG are qualified more often for PCI than for re-CABG. However, patients after prior CABG were not disqualified from surgery by the protocol. On admission, stable CAD was less frequent in Group $2(46 \%$ vs. $61.4 \%$; $p=0.021)$, and patients with NSTEMI were found more often $(22.2 \%$ vs. $7.8 \% ; p<0.001)$. Left ventricular ejection fraction (LVEF) was significantly lower in Group 2 (46 $\pm 11.4 \%$ vs. $51.4 \pm 11 \% ; p<0.001)$ with no significant differences in other echocardiographic parameters. The Euroscore II value was higher in Group 2 (2.72 \pm 2.01 vs. $2.15 \pm 2.16 ; p=0.007)$.

Table 2. Study population baseline characteristics.

\begin{tabular}{|c|c|c|c|c|}
\hline Variable & $\begin{array}{c}\text { Total } \\
n=459\end{array}$ & $\begin{array}{c}\text { Group } 1 \\
n=396\end{array}$ & $\begin{array}{c}\text { Group } 2 \\
n=63\end{array}$ & $\begin{array}{c}p \text {-Value } \\
\text { (Group } 1 \text { vs. Group 2) }\end{array}$ \\
\hline Age (y) & $68.4 \pm 9.4$ & $68 \pm 9.1$ & $70.9 \pm 10.9$ & 0.024 \\
\hline Gender (female) & $112(24.4 \%)$ & $90(22.7 \%)$ & $22(34.9 \%)$ & 0.036 \\
\hline $\mathrm{BMI}\left(\mathrm{kg} / \mathrm{m}^{2}\right)$ & $28.1 \pm 4.6$ & $28.1 \pm 4.4$ & $28.2 \pm 5.8$ & 0.353 \\
\hline Hypertension & 375 (81.7\%) & $326(82.3 \%)$ & $49(77.8 \%)$ & 0.386 \\
\hline Hyperlipidemia & $230(50.1 \%)$ & $203(51.2 \%)$ & $27(42.9 \%)$ & 0.215 \\
\hline CKD & $159(34.6 \%)$ & $125(31.6 \%)$ & $34(54 \%)$ & $<0.001$ \\
\hline DM & $164(35.7 \%)$ & $136(34.3 \%)$ & $28(44.4 \%)$ & 0.120 \\
\hline Stroke/TIA & $34(7.4 \%)$ & $29(7.3 \%)$ & $5(7.9 \%)$ & 0.863 \\
\hline COPD & $37(8.1 \%)$ & $29(7.3 \%)$ & $8(12.7 \%)$ & 0.145 \\
\hline PVD & $66(14.4 \%)$ & $56(14.1 \%)$ & $10(15.9 \%)$ & 0.716 \\
\hline $\mathrm{AF}$ & $59(12.9 \%)$ & $48(12.1 \%)$ & $11(17.5 \%)$ & 0.240 \\
\hline Smoking (current) & $168(36.6 \%)$ & $140(35.4 \%)$ & $28(44.4 \%)$ & 0.164 \\
\hline Prior MI & $227(49.5 \%)$ & $199(50.3 \%)$ & $28(44.4 \%)$ & 0.382 \\
\hline Stable CAD & $272(59.2 \%)$ & $243(61.4 \%)$ & $29(46 \%)$ & 0.021 \\
\hline Unstable CAD & $125(27.2 \%)$ & $108(27.3 \%)$ & $17(27 \%)$ & 0.962 \\
\hline NSTEMI & $45(9.8 \%)$ & $31(7.8 \%)$ & $14(22.2 \%)$ & $<0.001$ \\
\hline STEMI & $13(2.8 \%)$ & $10(2.5 \%)$ & $3(4.8 \%)$ & 0.558 \\
\hline Prior PCI LAD & $104(22.7 \%)$ & $91(23 \%)$ & $13(20.6 \%)$ & 0.672 \\
\hline Prior PCI LCX & $65(14.2 \%)$ & $59(14.9 \%)$ & $6(9.5 \%)$ & 0.253 \\
\hline Prior PCI RCA & $132(28.8 \%)$ & $118(29.8 \%)$ & $14(22.2 \%)$ & 0.217 \\
\hline Prior CABG & $92(20 \%)$ & $88(22.2 \%)$ & $4(6.3 \%)$ & 0.003 \\
\hline LVEDD (mm) & $51.6 \pm 7.7$ & $51.5 \pm 7.6$ & $52.4 \pm 8.2$ & 0.523 \\
\hline LVEF (\%) & $50.6 \pm 11.2$ & $51.4 \pm 11$ & $46 \pm 11.4$ & $<0.001$ \\
\hline EuroScore II & $2.32 \pm 2.13$ & $2.15 \pm 2.16$ & $2.72 \pm 2.01$ & 0.007 \\
\hline Syntax Score & $24.0 \pm 9.9$ & $23.2 \pm 9.7$ & $29.1 \pm 9.5$ & $<0.001$ \\
\hline 0-22 (low) & $230(50.1 \%)$ & $214(54 \%)$ & $16(25.4 \%)$ & $<0.001$ \\
\hline 23-32 (intermediate) & $145(31.6 \%)$ & $120(30.3 \%)$ & $25(39.7 \%)$ & 0.137 \\
\hline$\geq 33$ (high) & $84(18.3 \%)$ & $62(15.7 \%)$ & $22(34.9 \%)$ & $<0.001$ \\
\hline
\end{tabular}

BMI-Body Mass Index, CKD—Chronic Kidney Disease, DM-Diabetes Mellitus, TIA—Transient Ischemic Attack, COPD_Chronic Obstructive Pulmonary Disease, PVD—Peripheral Vascular Disease, AF-Atrial Fibrillation, MI-Myocardial Infarction, CAD_Coronary Artery Disease, PCI-Percutaneous Coronary Intervention, LADLeft Anterior Descending Artery, LCx-Left Circumflex, RCA-Right Coronary Artery, CABG-Coronary Artery Bypass Graft, LVEDD—Left Ventricular End Diastolic Diameter, LVEF-Left Ventricle Ejection Fraction. 


\subsection{CAD Characteristics}

The extent of coronary artery disease is shown in Table 3. The groups did not differ within the localization of the LM disease. Protected LM was more common in Group 1. The lack of right coronary artery support (i.e., recessive, critical stenosis, or occlusion of RCA) was more common in Group 2. The presence of non-LM lesions did not differ significantly in LAD and RCA. Still, it was found more frequently in non-ostial LCx in Group 2. The incidence of two- or three-vessel disease was also higher in Group 2. The frequency of Medina 1.1.1 bifurcation was significantly higher in Group 2, as well as the mean values of the Syntax score $(29.1 \pm 9.5$ vs. $23.2 \pm 9.7 ; p<0.001)$.

Table 3. Coronary artery disease characteristics.

\begin{tabular}{|c|c|c|c|c|}
\hline Variable & $\begin{array}{c}\text { Total } \\
n=459\end{array}$ & $\begin{array}{c}\text { Group } 1 \\
n=396\end{array}$ & $\begin{array}{c}\text { Group } 2 \\
n=63\end{array}$ & $\begin{array}{c}p \text {-Value } \\
\text { (Group } 1 \text { vs. Group 2) }\end{array}$ \\
\hline LM distal & $375(81.7 \%)$ & $319(80.1 \%)$ & $56(88.9 \%)$ & 0.087 \\
\hline LM bifurcation & $292(63.6 \%)$ & $249(62.9 \%)$ & $43(68.3 \%)$ & 0.410 \\
\hline LM trifurcation & $52(11.3 \%)$ & $43(10.9 \%)$ & $9(14.3 \%)$ & 0.425 \\
\hline LM calcification & $70(15.3 \%)$ & $54(13.6 \%)$ & $16(25.4 \%)$ & 0.016 \\
\hline LAD disease (not ostial) & $240(52.3 \%)$ & $202(51 \%)$ & $38(60.3 \%)$ & 0.167 \\
\hline LCx disease (not ostial) & $159(34.6 \%)$ & $130(32.8 \%)$ & $29(46 \%)$ & 0.041 \\
\hline Protected LM & $63(13.7 \%)$ & $62(15.7 \%)$ & $1(1.6 \%)$ & 0.003 \\
\hline RCA recessive (a) & $29(6.3 \%)$ & $23(5.8 \%)$ & $6(9.5 \%)$ & 0.260 \\
\hline RCA with critical stenosis (b) & $70(15.3 \%)$ & $54(13.6 \%)$ & $16(25.4 \%)$ & 0.016 \\
\hline RCA total occlusion (c) & $82(17.9 \%)$ & $68(17.2 \%)$ & $14(22.2 \%)$ & 0.331 \\
\hline Lack of RCA support to LM-CAD $(a+b+c)$ & $156(34 \%)$ & $124(31.3 \%)$ & $32(50.8 \%)$ & 0.002 \\
\hline \multicolumn{5}{|l|}{ Extent of diseased vessels } \\
\hline LM only & $126(27.5 \%)$ & $118(29.8 \%)$ & $8(12.7 \%)$ & 0.005 \\
\hline LM plus 1-vessel disease & $164(35.7 \%)$ & $144(36.4 \%)$ & $20(31.7 \%)$ & 0.477 \\
\hline LM plus 2-vessel disease & $116(25.3 \%)$ & $90(22.7 \%)$ & $26(41.3 \%)$ & 0.002 \\
\hline LM plus 3-vessel disease & $53(11.5 \%)$ & $44(11.1 \%)$ & $9(14.3 \%)$ & 0.464 \\
\hline \multicolumn{5}{|l|}{ Bifurcation Medina } \\
\hline 1.0 .0 & $94(20.5 \%)$ & $83(21 \%)$ & $11(17.5 \%)$ & 0.522 \\
\hline 1.0.1 & $37(8.1 \%)$ & $32(8.1 \%)$ & $5(7.9 \%)$ & 0.968 \\
\hline 1.1.0 & $91(19.8 \%)$ & $80(20.2 \%)$ & $11(17.5 \%)$ & 0.612 \\
\hline 1.1.1 & $70(15.3 \%)$ & $54(13.6 \%)$ & $16(25.4 \%)$ & 0.016 \\
\hline
\end{tabular}

LM—Left Main, LAD—Left Anterior Descending Artery, LCx—Left Circumflex Artery, RCA—Right Coronary Artery, LM-CAD—Left Main Coronary Artery Disease.

\subsection{LM PCI Procedure}

The PCI procedure characteristics are shown in Table 4. An early success rate was very high (99\%) and did not differ between the groups. The number ( $1.9 \pm 0.9$ vs. $1.63 \pm 0.79$; $p=0.012)$ as well as the total length $(43.7 \pm 22.3$ vs. $37.1 \pm 21.2 ; p=0.009)$ of implanted stents were significantly higher in Group 2. Periprocedural fluoroscopy time and a dose of radiation did not differ significantly. Artery access was similar in both groups, and it was more often a radial approach. All LM lesions were stented with second-generation DESs. Various stenting techniques were used. Two-stent techniques were more common in Group $2(33.3 \%$ vs. $16.2 \% ; p=0.001)$. Among the two-stent techniques, the crush technique was the most common (48.2\%). All LM procedures were carried out without mechanical LV support. 
Table 4. Left Main PCI procedure characteristics.

\begin{tabular}{|c|c|c|c|c|}
\hline Variable & $\begin{array}{c}\text { Total } \\
n=459\end{array}$ & $\begin{array}{c}\text { Group } 1 \\
n=396\end{array}$ & $\begin{array}{c}\text { Group } 2 \\
n=63\end{array}$ & $\begin{array}{c}p \text {-Value } \\
\text { (Group } 1 \text { vs. Group 2) }\end{array}$ \\
\hline PCI success & $456(99.3 \%)$ & $393(99.2 \%)$ & $63(100 \%)$ & 0.882 \\
\hline Number of stents & $1.67 \pm 0.81$ & $1.63 \pm 0.79$ & $1.9 \pm 0.9$ & 0.012 \\
\hline Total length of implanted stents (mm) & $38.0 \pm 21.5$ & $37.1 \pm 21.2$ & $43.7 \pm 22.3$ & 0.009 \\
\hline Fluoroscopy time $(\mathrm{min})$ & $17.47 \pm 9.25$ & $17.16 \pm 9.17$ & $19.42 \pm 9.57$ & 0.060 \\
\hline Radiation dose (mGy) & $1442 \pm 877$ & $1427 \pm 879$ & $1531 \pm 871$ & 0.370 \\
\hline Contrast volume (mL) & $247.4 \pm 94.2$ & $248.1 \pm 96.9$ & $242.9 \pm 76.3$ & 0.804 \\
\hline \multicolumn{5}{|l|}{ Arterial Access site } \\
\hline Radial & $270(58.8 \%)$ & $235(59.3 \%)$ & $35(55.6 \%)$ & \multirow{2}{*}{0.570} \\
\hline Femoral & $189(41.2 \%)$ & $161(40.7 \%)$ & $28(44.4 \%)$ & \\
\hline Stenting LM only & $57(12.4 \%)$ & $50(12.6 \%)$ & $7(11.1 \%)$ & 0.735 \\
\hline \multicolumn{5}{|l|}{ Stenting LM bifurcation } \\
\hline One-stent technique & $317(69.1 \%)$ & $282(71.2 \%)$ & $35(55.5 \%)$ & 0.013 \\
\hline Two-stents technique & $85(18.5 \%)$ & $64(16.2 \%)$ & $21(33.3 \%)$ & 0.001 \\
\hline Two-stents techniques & Total $n=85$ & $n=64$ & $n=21$ & \\
\hline Crush & $30(35.3 \%)$ & $18(28.1 \%)$ & $12(57.1 \%)$ & 0.016 \\
\hline DK-Crush & $11(12.9 \%)$ & $9(14.1 \%)$ & $2(9.5 \%)$ & 0.879 \\
\hline Cullote & $1(1.1 \%)$ & $0(0 \%)$ & $1(4.8 \%)$ & 0.247 \\
\hline T-stenting & $19(22.4 \%)$ & $1523.4 \%)$ & $4(19 \%)$ & 0.905 \\
\hline Provisional stenting & $24(28.2 \%)$ & $22(34.3 \%)$ & $2(9.5 \%)$ & 0.028 \\
\hline
\end{tabular}

PCI-Percutaneous Coronary Intervention, LM—Left Main, DK-Crush—Double Kissing Crush Technique.

\subsection{Clinical Outcomes}

Troponin elevation after PCI was relatively high in both groups (57.1\% vs. $46.7 \%$; $p=0.136$ ) (Table 5). All periprocedural complications, including stroke, tamponade, artery dissection, and contrast-induced nephropathy $(12.7 \%$ vs. $7.8 \% ; p=0.198)$, as well as periprocedural mortality and myocardial infarction type 4 a $(7.9 \%$ vs. $4 \% ; p=0.294)$, did not differ between the groups.

Table 5. Periprocedural outcomes.

\begin{tabular}{|c|c|c|c|c|}
\hline Variable & $\begin{array}{c}\text { Total } \\
n=459\end{array}$ & $\begin{array}{c}\text { Group } 1 \\
n=396\end{array}$ & $\begin{array}{c}\text { Group } 2 \\
n=63\end{array}$ & $\begin{array}{c}p \text {-Value } \\
\text { (Group } 1 \text { vs. Group 2) }\end{array}$ \\
\hline Significant troponin elevation $(5 \times)$ after PCI & $222(48.4 \%)$ & $185(46.7 \%)$ & $36(57.1 \%)$ & 0.136 \\
\hline Myocardial Infarction & $21(4.6 \%)$ & $16(4 \%)$ & $5(7.9 \%)$ & 0.294 \\
\hline In-hospital Death & $2(0.4 \%)$ & $2(0.5 \%)$ & $0(0 \%)$ & 0.642 \\
\hline Stroke & $1(0.2 \%)$ & $0(0 \%)$ & $1(1.6 \%)$ & 0.137 \\
\hline Tamponade & $2(0.4 \%)$ & $2(0.5 \%)$ & $0(0 \%)$ & 0.642 \\
\hline Pulmonary oedema & $1(0.2 \%)$ & $0(0 \%)$ & $1(1.6 \%)$ & 0.137 \\
\hline Dissection of aorta & $1(0.2 \%)$ & $1(0.3 \%)$ & $0(0 \%)$ & 0.291 \\
\hline Perforation of femoral artery & $1(0.2 \%)$ & $1(0.3 \%)$ & $0(0 \%)$ & 0.291 \\
\hline Contrast induced nephropathy & $17(3.7 \%)$ & $12(3 \%)$ & $5(7.9 \%)$ & 0.120 \\
\hline
\end{tabular}

PCI-Percutaneous Coronary Intervention.

The median follow-up was 808 days (min: 366 days, max: 1616 days, interquartile range: 606 days). At long-term follow-up, a higher all-cause mortality rate was observed in Group $2(26 \%$ vs. $21 \%$; $p=0.031)$ (Figure 2 ). 


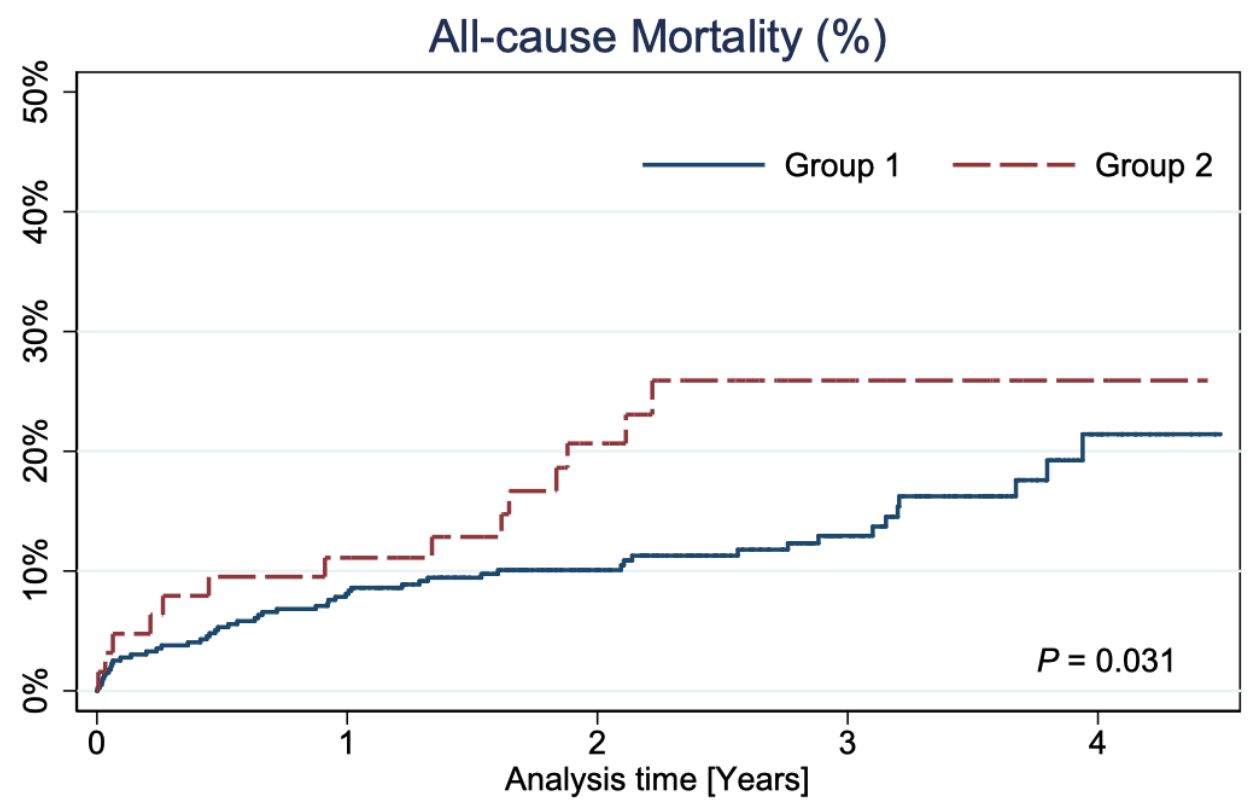

Figure 2. Kaplan-Meier curves showing all-cause mortality.

\section{Discussion}

To the best of our knowledge, based on the literature review, the current study is the first to report the long-term outcomes of patients with LM-CAD disqualified from CABG in a real-world setting.

The risk models, used in current ESC guidelines and based on SYNTAX score, rely entirely on anatomical characteristics, and define three categories of risk (low, intermediate, and high) based on conventional thresholds ( $\leq 22,23-32$, and $\geq 33$, respectively) [1]. Current guidelines indicate that $\mathrm{PCI}$ is an appropriate alternative to CABG in LM disease with low anatomical complexity of CAD (class Ia of recommendation) and should be considered for PCI in LM with intermediate CAD (class IIa of recommendation) [13]. In patients with LMCAD and high SYNTAX score, the guidelines suggest better survival after CABG, so PCI should not be undertaken in that subgroup of patients (PCI class III of recommendation) [13] However, the real risk is imprecise due to the lack of these patients in large randomized clinical trials. Therefore, the personalized patient-to-patient Heart Team decision with detailed analysis of the individual clinical status and cardiac and non-cardiac comorbidities is crucial here.

Our study provides information about real-life LM PCI and includes patients who should have been qualified for CABG but for some reasons were not eligible for the surgery. This population is normally excluded from clinical trials, and the available information about this group of patients is insufficient. The principal finding from the present study is that PCI of LM in patients who were disqualified from CABG for various cardiovascular and non-cardiovascular reasons was a safe procedure with similar complication rates as in patients who had the same recommendation class to PCI or CABG. Our results showed that patients, who underwent LM PCI in a high-volume center, also those disqualified from CABG, had favorable short- and long-term (median: 808 days) outcomes. If we compared the group of patients qualified originally for PCI (Group 1) and those disqualified from CABG (Group 2) treated with LM PCI, there were no differences between the groups in periprocedural complications rates or occurrence of in-hospital cardiovascular events and death. These perioperative values obtained in our study are similar to those presented in the NOBLE or EXCEL studies. The periprocedural myocardial infarction after PCI occurred in $5 \%$ in the NOBLE study, $3.6 \%$ in the EXCEL study, and $4.6 \%$ in our study. The in-hospital death rate was $<1 \%$ in the NOBLE study, and $0.4 \%$ in our study $[17,21]$. Our short-term results are also consistent with outcomes of other registries [22-24]. 
In the long-term follow-up, with the median of 808 days, significantly higher mortality in Group 2 than Group 1 was noted (26\% vs. $21 \% ; p=0.031)$. Considering the characteristics of the disqualified group, this is understandable, and the results obtained still demonstrate a favorable prognosis. Additionally, our long-term mortality outcomes do not diverge from the results of other real-world investigations [25], and we cannot simply compare these results with the results of selected, large, randomized trials such as PRECOMBAT, EXCEL, or NOBLE [15-17]. It should be emphasized that the real-world results presented in our study showed that the frequency of comorbidities was somehow higher than in selected RCTs populations [16,17]. In patients disqualified from CABG, the CKD rate was especially high (54\%) and significantly higher than in Group 1, where the CKD rate was $31.6 \%(p<0.001)$. This does not correspond with the results from the EXCEL trial [16], where in the group treated with PCI, renal insufficiency (defined as GFR $<60 \mathrm{~mL} / \mathrm{min}$ ) occurred only in 17.7\% [16]. In addition, in our analysis, patients in Group 2 had NSTEMI at admission more often (22.2\%) than those from the EXCEL study, where that percentage was only $13.2 \%$ [16]. Our observation showed similar outcomes, despite the worse clinical status of patients resulting mainly from the large NSTEMI rate and a greater percentage of comorbidities affecting prognosis. The survival rates of patients in Group 1 in our study, with a $21.0 \%$ mortality rate after 5 years, agree with large LM registries, i.e., LE MANS or MAIN-COMPARE Registry [22,26].

PCI of LM-CAD is a complex procedure that requires procedural planning based on clinical and anatomical characteristics with an individual choice of stenting technique $[12,27]$. In our investigation, as in the EXCEL study, only second-generation DESs were used [16]. The stent strategy is generally based on the burden of atherosclerotic disease at the level of the LCx ostium. The diameter stenosis of $\geq 70 \%$, lesion length of $>10 \mathrm{~mm}$, and / or a difficult side branch access indicate a complex lesion that typically requires upfront a two-stents technique. In all other cases, a provisional approach is preferable [28]. In our study, the two-stent technique was more often used in the group disqualified from CABG because these patients presented with more complex bifurcation lesions. Moreover, the rate of bifurcations Medina 1.1.1 was also higher $(p=0.016)$. There is a widespread controversy in the literature regarding choosing a one- or two-stent technique for the treatment of LM bifurcation lesions. From time to time, the experts' consensus tries to refine the data and establish up-to-date recommendations [29]. Non-randomized data uniformly suggests that outcomes are worse with a two-stent strategy [30-32], but randomized data support the double kissing (DK) crush technique for a true LM bifurcation [33] and prefers it over culotte [34]. A recent randomized controlled study showed that among patients with true LM bifurcation stenosis requiring intervention, fewer major adverse cardiac events occurred with a stepwise provisional approach than with planned dual stenting. However, the difference was not statistically significant [35].

Additionally, in Group 2, atherosclerotic lesions requiring revascularization in other parts of coronary arteries, especially in LCx $(p=0.041)$, and LM with the 2-vessel disease were observed more frequently $(p=0.002)$. Consequently, the total number of implanted stents, as well as the total length of stents, were higher, which can indirectly affect the outcomes [36]. It should be emphasized that despite the higher total stent length in Group 2 in our study, the numbers in both groups still did not exceed the length obtained in the other studies with second-generation DESs [27]. The complexity of the procedure was higher in Group 2 also due to the lack of support from RCA, which occurred more often in those patients $(p=0.002)$. Despite using more complex techniques in Group 2, no significant increase in troponin levels or myocardial infarction type 4 a rates were observed if compared with the other group. Most patients analyzed in our study had distal LM bifurcation or trifurcation disease with involvement of at least one side branch (MEDINA 1.1.1, 1.0.1, 1.1.0), which was similar to the population from the EXCEL study and the recently published BBK-LM Registry $[37,38]$.

All findings indicate that patients in Group 2 had more advanced CAD and, following current guidelines, should be the candidates for CABG [13]. Our results showed the safety 
of PCI procedure with a very high success rate also in these patients, giving them a chance for better outcomes compared with conservative treatment. The comparison with previous trials should be made with caution due to the lack of information of patients with a high SYNTAX score ( $\geq 33$ ) undergoing LM PCI. The EXCEL study analyzed only patients with a low and intermediate risk assessed at site according to the SYNTAX score [16]. However, after evaluation by the core laboratory, it was found that there was a group of patients with a high SYNTAX score $(\geq 33)$ [37]. Therefore, this study confirmed the safety and effectiveness of LM PCI in patients with a high SYNTAX score, who were also presented in our study [37]. In the NOBLE study, in a small group of 46 patients with a high SYNTAX score, the MACCE rate (death from any cause, non-procedural myocardial infarction, repeat revascularization, or stroke) was of over 30\% [17]. The long-term results of our study presented a slightly better prognosis in high SYNTAX score group with a mortality of approximately $25 \%$.

The presented study is an analysis of a real-world cohort of patients. In contrast to other huge trials, it described patients with LM disease disqualified from the CABG procedure, who are mainly excluded from clinical trials. However, our analysis has several limitations. Firstly, the presented study was a prospective registry, but not all clinical data were available. Secondly, troponin analysis was not available in the entire analyzed population. Thirdly, this was a real-world study, and LM disease was not a homogenous disease. Outcomes could have been affected by the location of the disease (ostial/shaft/bifurcation), the complexity of the lesion, and distal CAD. Finally, the presented study analyzed inhospital outcomes, as well as the long-term outcomes; however, the long-term follow-up showed only all-cause mortality rates.

\section{Conclusions}

LM PCI in patients disqualified from CABG is an effective and safe procedure with low in-hospital complication rates. Long-term results in this group of patients are satisfactory. To provide an individualized approach, the data should be considered by physicians and patients together when deciding on the revascularization strategy because this life-saving treatment remains the only option for such patients.

Author Contributions: Conceptualization, W.J.S., M.K.-O., W.S. and M.G.; Methodology, W.J.S. and M.K.-O.; Validation, M.L. and M.G.; Formal Analysis, W.J.S. and M.K.-O.; Investigation, W.J.S., M.K.-O., M.L., A.A., W.S., S.G., P.M., M.P. and M.G.; Resources, M.L.; Data Curation, W.J.S. and M.K.-O.; Writing-Original Draft Preparation, W.J.S. and M.K.-O.; Writing-Review \& Editing, M.K.-O. and M.G.; Visualization, W.J.S. and M.K.-O.; Supervision, M.K.-O. and M.G.; Project Administration, W.J.S. All authors have read and agreed to the published version of the manuscript.

Funding: This research received no external funding.

Institutional Review Board Statement: The study was conducted according to the guidelines of the Declaration of Helsinki and approved by the Institutional Review Board (or Ethics Committee) of Poznan University of Medical Sciences.

Informed Consent Statement: Not applicable.

Data Availability Statement: The data presented in this study are available on request from the corresponding author.

Acknowledgments: The authors thank JO Medical Solutions for providing medical writing support following Good Publication Practice (GPP3) guidelines (http:/ / www.ismpp.org/gpp3, accessed date: 21 January 2022).

Conflicts of Interest: The authors declare no conflict of interest. 


\section{References}

1. Sianos, G.; Morel, M.-A.; Kappetein, A.P.; Morice, M.-C.; Colombo, A.; Dawkins, K.; Brand, M.V.D.; Van Dyck, N.; Russell, M.E.; Mohr, F.W.; et al. The SYNTAX Score: An angiographic tool grading the complexity of coronary artery disease. EuroIntervention 2005, 1, 219-227. [PubMed]

2. El-Menyar, A.A.; Al Suwaidi, J.; Holmes, D.R. Left Main Coronary Artery Stenosis: State-of-the-Art. Curr. Probl. Cardiol. 2007, 32, 103-193. [CrossRef] [PubMed]

3. Hitchcock, J.F.; Robles de Medina, E.O.; Jambroes, G. Angioplasty of the left main coronary artery for isolated left main coronary artery disease. J. Thorac. Cardiovasc. Surg. 1983, 85, 880-884. [CrossRef]

4. Conley, M.J.; Ely, R.L.; Kisslo, J.; Lee, K.L.; McNeer, J.F.; Rosati, R.A. The prognostic spectrum of left main stenosis. Circulation 1978, 57, 947-952. [CrossRef]

5. Herrick, J.B. Clinical features of sudden obstruction of the coronary arteries. J. Am. Med. Assoc. 1912, 23, 2015-2022. [CrossRef]

6. Favaloro, R.G. Saphenous Vein Autograft Replacement of Severe Segmental Coronary Artery Occlusion: Operative Technique. Ann. Thorac. Surg. 1968, 5, 334-339. [CrossRef]

7. Killip, T.; Passamani, E.; Davis, K. Coronary Artery Surgery study (CASS): A randomized trial of coronary artery bypass surgery. Surviv. Data Circ. 1983, 68, 939-950.

8. Group ECSS. Long-term results of prospective randomized study or coronary artery bypass surgery in stable angina pectoris. Lancet 1982, 2, 1173-1180.

9. Yusuf, S.; Zucker, D.; Passamani, E.; Peduzzi, P.; Takaro, T.; Fisher, L.; Kennedy, J.; Davis, K.; Killip, T.; Norris, R.; et al. Effect of coronary artery bypass graft surgery on survival: Overview of 10-year results from randomised trials by the Coronary Artery Bypass Graft Surgery Trialists Collaboration. Lancet 1994, 344, 563-570. [CrossRef]

10. Morice, M.-C.; Serruys, P.W.; Kappetein, A.P.; Feldman, T.E.; Ståhle, E.; Colombo, A.; Mack, M.J.; Holmes, D.R.; Torracca, L.; van Es, G.-A.; et al. Outcomes in patients with de novo left main disease treated with either percutaneous coronary intervention using paclitaxel-eluting stents or coronary artery bypass graft treatment in the Synergy Between Percutaneous Coronary Intervention with TAXUS and Cardiac Surgery (SYNTAX) trial. Circulation 2010, 121, 2645-2653.

11. Park, S.-J.; Kim, Y.-H.; Park, D.-W.; Yun, S.-C.; Ahn, J.-M.; Song, H.G.; Lee, J.-Y.; Kim, W.-J.; Kang, S.-J.; Lee, S.-W.; et al. Randomized trial of stents versus bypass surgery for left main coronary artery disease. N. Engl. J. Med. 2011, 364, 1718-1727. [CrossRef] [PubMed]

12. Rab, T.; Sheiban, I.; Louvard, Y.; Sawaya, F.J.; Zhang, J.J.; Chen, S.L. Current Interventions for the Left Main Bifurcation. JACC Cardiovasc. Interv. 2017, 10, 849-865. [CrossRef] [PubMed]

13. Neumann, F.J.; Sousa-Uva, M.; Ahlsson, A.; Alfonso, F.; Banning, A.P.; Benedetto, U.; Byrne, R.A.; Collet, J.P.; Falk, V.; Head, S.J.; et al. 2018 ESC/EACTS Guidelines on myocardial revascularization. Eur. Heart J. 2018, 40, 87-165. [CrossRef] [PubMed]

14. Morice, M.-C.; Serruys, P.W.; Kappetein, A.P.; Feldman, T.E.; Ståhle, E.; Colombo, A.; Mack, M.J.; Holmes, D.R.; Choi, J.W.; Ruzyllo, W.; et al. Five-Year Outcomes in Patients With Left Main Disease Treated with Either Percutaneous Coronary Intervention or Coronary Artery Bypass Grafting in the Synergy Between Percutaneous Coronary Intervention with Taxus and Cardiac Surgery Trial. Circulation 2014, 129, 2388-2394. [CrossRef]

15. Ahn, J.M.; Roh, J.H.; Kim, Y.H.; Park, D.W.; Yun, S.C.; Lee, P.H.; Chang, M.; Park, H.W.; Lee, S.W.; Lee, C.W.; et al. Randomized Trial of Stents Versus Bypass Surgery for Left Main Coronary Artery Disease: 5-Year Outcomes of the PRECOMBAT Study. J. Am. Coll. Cardiol. 2015, 65, 2198-2206. [CrossRef]

16. Stone, G.W.; Sabik, J.F.; Serruys, P.W.; Simonton, C.A.; Généreux, P.; Puskas, J.; Kandzari, D.E.; Morice, M.-C.; Lembo, N.; Brown, W.M.; et al. Everolimus-eluting stents or bypass surgery for left main coronary artery disease. N. Engl. J. Med. 2016, 375, 2223-2235. [CrossRef]

17. Mäkikallio, T.; Holm, N.; Lindsay, M.; Spence, M.S.; Erglis, A.; Menown, I.B.A.; Trovik, T.; Eskola, M.; Romppanen, H.; Kellerth, T.; et al. Percutaneous coronary angioplasty versus coronary artery bypass grafting in treatment of unprotected left main stenosis (NOBLE): A prospective, randomised, open-label, non-inferiority trial. Lancet 2016, 388, 2743-2752. [CrossRef]

18. Medina, A.; Suarez de Lezo, J.; Pan, M. A new classification of coronary bifurcation lesions. Rev. Esp. Cardiol. 2006, 59, 183. [CrossRef]

19. Thygesen, K.; Alpert, J.S.; Jaffe, A.S.; Chaitman, B.R.; Bax, J.J.; Morrow, D.A.; White, H.D.; Executive Group on behalf of the Joint European Society of Cardiology (ESC)/American College of Cardiology (ACC)/American Heart Association (AHA)/World Heart Federation (WHF) Task Force for the Universal Definition of Myocardial Infarction. Fourth Universal Definition of Myocardial Infarction (2018). J. Am. Coll. Cardiol. 2018, 72, 2231-2264. [CrossRef]

20. Siersbæk-Nielsen, K.; Molholm Hansen, J.; Kampmann, J.; Kristensen, M. Rapid Evaluation of Creatinine Clearance. Lancet 1971, 297, 1133-1134. [CrossRef]

21. Ben-Yehuda, O.; Chen, S.; Redfors, B.; McAndrew, T.; Crowley, A.; Kosmidou, I.; Kandzari, D.E.; Puskas, J.D.; Morice, M.-C.; Taggart, D.P.; et al. Impact of large periprocedural myocardial infarction on mortality after percutaneous coronary intervention and coronary artery bypass grafting for left main disease: An analysis from the EXCEL trial. Eur. Heart J. 2019, 40, 1930-1941. [CrossRef] [PubMed]

22. Buszman, P.E.; Buszman, P.P.; Kiesz, R.S.; Bochenek, A.; Trela, B.; Konkolewska, M.; Wallace-Bradley, D.; Wilczyński, M.; Banasiewicz-Szkróbka, I.; Peszek-Przybyla, E.; et al. Early and Long-Term Results of Unprotected Left Main Coronary Artery Stenting. J. Am. Coll. Cardiol. 2009, 54, 1500-1511. [CrossRef] [PubMed] 
23. Park, D.-W.; Kim, Y.-H.; Yun, S.-C.; Lee, J.-Y.; Kim, W.-J.; Kang, S.-J.; Lee, S.-W.; Lee, C.-W.; Kim, J.-J.; Choo, S.-J.; et al. Long-term outcomes after stenting versus coronary artery bypass grafting for unprotected left main coronary artery disease: 10-year results of bare-metal stents and 5-year results of drug-eluting stents from the ASAN-MAIN (ASAN Medical Center-Left MAIN Revascularization) Registry. J. Am. Coll. Cardiol. 2010, 56, 1366-1375. [PubMed]

24. Chieffo, A.; Tanaka, A.; Giustino, G.; Briede, I.; Sawaya, F.J.; Daemen, J.; Kawamoto, H.; Meliga, E.; D’ Ascenzo, F.; Cerrato, E.; et al. The DELTA 2 Registry. JACC Cardiovasc. Interv. 2017, 10, 2401-2410. [CrossRef] [PubMed]

25. Lu, T.-M.; Lee, W.-L.; Hsu, P.-F.; Lin, T.-C.; Sung, S.-H.; Wang, K.-L.; Huang, S.-S.; Chan, W.-L.; Shih, C.-C.; Lin, S.-J.; et al Long-term results of stenting versus coronary artery bypass surgery for left main coronary artery disease-A single-center experience. J. Chin. Med. Assoc. 2016, 79, 356-362. [CrossRef]

26. Park, D.-W.; Seung, K.B.; Kim, Y.-H.; Lee, J.-Y.; Kim, W.-J.; Kang, S.-J.; Lee, S.-W.; Lee, C.W.; Park, S.-W.; Yun, S.-C.; et al. Long-Term Safety and Efficacy of Stenting Versus Coronary Artery Bypass Grafting for Unprotected Left Main Coronary Artery Disease. J. Am. Coll. Cardiol. 2010, 56, 117-124. [CrossRef]

27. Lee, P.H.; Ahn, J.M.; Chang, M.; Baek, S.; Yoon, S.H.; Kang, S.J.; Lee, S.W.; Kim, Y.H.; Lee, C.W.; Park, S.W.; et al. Left Main Coronary Artery Disease. J. Am. Coll. Cardiol. 2016, 68, 1233-1246. [CrossRef]

28. Fajadet, J.; Capodanno, D.; Stone, G.W. Management of left main disease: An update. Eur. Heart J. 2019, 40, 1454-1466. [CrossRef]

29. Burzotta, F.; Lassen, J.F.; Banning, A.; Lefèvre, T.; Hildick-Smith, D.; Chieffo, A.; Darremont, O.; Pan, M.; Chatzizisis, Y.S.; Albiero, R.; et al. Percutaneous coronary intervention in left main coronary artery disease: The 13th consensus document from the European Bifurcation Club. EuroIntervention 2018, 14, 112-120. [CrossRef]

30. Kang, D.-Y.; Ahn, J.-M.; Yun, S.-C.; Park, H.; Cho, S.-C.; Kim, T.O.; Park, S.; Lee, P.H.; Lee, S.-W.; Park, S.-W.; et al. Long-Term Clinical Impact of Intravascular Ultrasound Guidance in Stenting for Left Main Coronary Artery Disease. Circ. Cardiovasc. Interv. 2021, 14, e011011. [CrossRef]

31. Kim, W.-J.; Kim, Y.-H.; Park, D.-W.; Yun, S.-C.; Lee, J.-Y.; Kang, S.-J.; Lee, S.-W.; Lee, C.W.; Park, S.-W.; Park, S.-J. Comparison of single-versus two-stent techniques in treatment of unprotected left main coronary bifurcation disease. Catheter. Cardiovasc. Interv. 2011, 77, 775-782. [CrossRef]

32. Choi, K.H.; Bin Song, Y.; Lee, J.M.; Park, T.K.; Yang, J.H.; Hahn, J.-Y.; Choi, J.-H.; Choi, S.-H.; Kim, H.-S.; Chun, W.J.; et al. Prognostic effects of treatment strategies for left main versus non-left main bifurcation percutaneous coronary intervention with current-generation drug-eluting stent. Circ. Cardiovasc. Interv. 2020, 13, e008543. [CrossRef]

33. Zhang, J.-J.; Ye, F.; Xu, K.; Kan, J.; Tao, L.; Santoso, T.; Munawar, M.; Tresukosol, D.; Li, L.; Sheiban, I.; et al. Multicentre, randomized comparison of two-stent and provisional stenting techniques in patients with complex coronary bifurcation lesions: The DEFINITION II trial. Eur. Heart J. 2020, 41, 2523-2536. [CrossRef]

34. Chen, S.L.; Xu, B.; Han, Y.L.; Sheiban, I.; Zhang, J.J.; Ye, F.; Kwan, T.W.; Paiboon, C.; Zhou, Y.J.; Lv, S.Z.; et al. Comparison of double kissing crush versus Culotte stenting for unprotected distal left main bifurcation lesions: Results from a multicenter, randomized, prospective DKCRUSH-III study. J. Am. Coll. Cardiol. 2013, 61, 1482-1488. [CrossRef] [PubMed]

35. Hildick-Smith, D.; Egred, M.; Banning, A.; Brunel, P.; Ferenc, M.; Hovasse, T.; Wlodarczak, A.; Pan, M.; Schmitz, T.; Silvestri, M.; et al. The European bifurcation club Left Main Coronary Stent study: A randomized comparison of stepwise provisional vs. systematic dual stenting strategies (EBC MAIN). Eur. Heart J. 2021, 42, 3829-3839. [CrossRef] [PubMed]

36. Suh, J.; Park, D.W.; Lee, J.Y.; Jung, I.H.; Lee, S.W.; Kim, Y.H.; Lee, C.W.; Cheong, S.S.; Kim, J.J.; Park, S.W.; et al. The Relationship and Threshold of Stent Length With Regard to Risk of Stent Thrombosis after Drug-Eluting Stent Implantation. JACC Cardiovasc. Interv. 2010, 3, 383-389. [CrossRef]

37. Kandzari, D.E.; Gershlick, A.H.; Serruys, P.W.; Leon, M.B.; Morice, M.-C.; Simonton, C.A.; Lembo, N.J.; Banning, A.P.; Merkely, B.; van Boven, A.J.; et al. Outcomes Among Patients Undergoing Distal Left Main Percutaneous Coronary Intervention. Circ. Cardiovasc. Interv. 2018, 11, e007007. [CrossRef]

38. Ferenc, M.; Banholzer, N.; Hochholzer, W.; Mashayekhi, K.; Comberg, T.; Rothe, J.; Valina, C.M.; Toma, A.; Löffelhardt, N.; Gick, M.; et al. Long-term results after PCI of unprotected distal left main coronary artery stenosis: The Bifurcations Bad Krozingen (BBK)-Left Main Registry. Clin. Res. Cardiol. 2019, 108, 175-184. [CrossRef] [PubMed] 